\title{
DESAIN LOGO KERUPUK MIE “KEMBANG MATAHARI" SEBAGAI UPAYA MENINGKATKAN CITRA
}

\author{
Iis Purnengsih' ${ }^{1}$, Yayah Rukiah², Dendi Pratama ${ }^{3}$ dan Angga Kusuma Dawami ${ }^{4}$ \\ 1,2,3,4 Program Studi Desain Komunikasi Visual, Universitas Indraprasta PGRI \\ E-Mail: iispurningsih@unindra.ac.id
}

Masuk :16-04-2019, revisi: 17-09-2019, diterima untuk diterbitkan : 18-09-2019

\begin{abstract}
ABSTRAK
Kerupuk Mie merek "Kembang Matahari" adalah salah satu produk unggulan daerah di Kabupaten Bogor yang berdiri sejak tahun 1977. Pemasaran yang kurang maksimal membuat Kerupuk Mie "Kembang Matahari” banyak ditiru, dan akhirnya menurunkan penjualannya. Perusahaan Kerupuk Mie "Kembang Matahari” harus bekerja keras untuk meningkatkan omzet penjualan. Dalam hal ini, salah satu upaya untuk meningkatkan omzet penjualan adalah dengan membuat desain logo yang menarik. Dan perusahaan Kerupuk Mie "Kembang Matahari” harus semaksimal mungkin untuk membentuk sebuah identitas yang kuat pada desain kemasan. Dengan adanya identitas yang kuat tersebut, sebuah perusahaan akan menjadi lebih dikenal oleh konsumen. Tujuan dari perancangan desain kemasan Kerupuk Mie"Kembang Matahari" adalah untuk menghasilkan desain kemasan dan logo Kerupuk Mie "Kembang Matahari". Perancangan akan dilaksanakan dengan metode penelitian kualitatif secara deskriptif dengan melakukan observasi, wawancara, dokumentasi, studi literature dan studi kompetitor untuk mendapatkan data sebagai konsep perancangan desain kemasan Kerupuk Mie "Kembang Matahari". Analisis data dengan menggunakan beberapa tahapan yaitu reduksi data, penyajian data, dan verifikasi kesimpulan. Setelah menganalisis data, ditemukan sebuah kata kunci "Asli" untuk perancangan desain logo . Konsep "Asli" dalam perancangan desain logo ini bermakna sesuatu yang bisa dipercaya. Hasil dari perancangan desain logo ini adalah upaya untuk meningkatkan citra dari logo Kerupuk Mie "Kembang Matahari”.
\end{abstract}

Kata Kunci: Perancangan Logo, Kerupuk Mie, Kembang Matahari, Citra

\begin{abstract}
The "Kembang Matahari" brand of Noodle Crackers is one of many flagship regional products in Bogor Regency which was established in 1977. Inadequate marketing of "Kembang Matahari" Noodle Crackers opened doors for imitation products, and ultimately reduced sales. "Kembang Matahari" Noodle Crackers Company must work hard to increase sales turnover. In this case, one of the efforts to increase sales turnover is by coming up with an attractive logo design and "Kembang Matahari" Noodle Crackers company must do its best to form a strong identity on packaging design. With this strong identity, the company will become better known by consumers. The purpose of designing "Kembang Matahari" Noodle Crackers packaging design is to produce both the "Kembang Matahari" Noodle Crackers packaging and logo design. The design will be carried out using descriptive qualitative research method by conducting observations, interviews, documentation, literature studies and competitor studies to obtain data as a design concept for the "Kembang Matahari" Noodle Crackers packaging design. Data analysis was conducted through several stages, from data reduction, data presentation, to verification of conclusions. After analyzing the data, the keyword "Original" was used for designing the logo. The concept of "Original" in the design of this logo means that it can be trusted. The result of this logo design is an effort to improve the image of the "Kembang Matahari" Noodle Cracker logo.
\end{abstract}

Keywords: Logo Design, Noodle Crackers, Kembang Matahari, Image 


\section{PENDAHULUAN}

\section{Latar Belakang}

Kerupuk merupakan makanan khas di Indonesia yang banyak dikenal oleh masyarakat Indonesia sebagai pendamping makanan utama di piring-piring makanan khas lain dari Indonesia. Salah satu kerupuk yang tersedia banyak di wilayah Jawa Barat adalah Kerupuk Mie, dimana kerupuk tersebut banyak diproduksi dan sekarang menjadi ciri khas dari Kabupaten Bogor. Kerupuk Mi Kuning banyak tersedia ketika bulan Puasa. Sebagai kudapan atau teman untuk makan asinan maupun hanya dengan sambal kacang. Wilayah Karadenan, Bogor masyarakatnya selalu membuat Krupuk Mi untuk pasokan di Jabodetabek. Pembuatan produk unggulan di wilayah ini yang menjadikan masyarakat di Karadenan, terus bisa menjadikan Kerupuk sebagai mata pencaharian. Salah satunya adalah Pabrik Kerupuk Mi "Kembang Matahari" yang telah beroperasi lebih dari 10 tahun lalu.

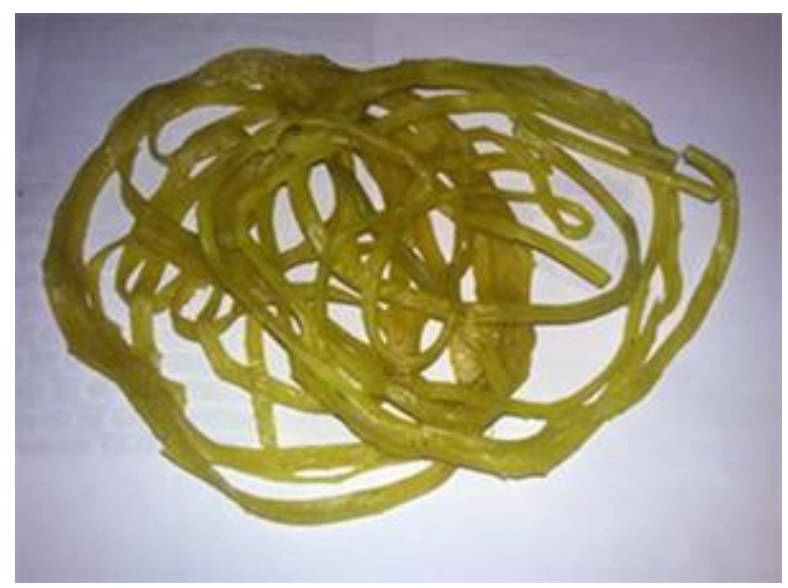

Gambar 1. Kerupuk Mie Kuning Bogor

Sumber: Tim Peneliti, 2018

Kerupuk mie tersebut banyak diproduksi di kabupaten Bogor, bahkan menjadi ciri khas dari Kabupaten Bogor. Kerupuk Mie Kuning banyak tersedia ketika bulan Puasa. Sebagai kudapan atau teman untuk makan asinan maupun hanya dengan sambal kacang. Wilayah Karadenan, Bogor masyarakatnya selalu membuat Krupuk Mie untuk pasokan di Jabodetabek. Pembuatan produk unggulan di wilayah ini yang menjadikan masyarakat di Karadenan, terus bisa menjadikan Kerupuk sebagai mata pencaharian. Salah satunya adalah Pabrik Kerupuk Mi "Kembang Matahari" yang telah beroperasi dari tahun 1977. Pemilik usaha Mie Kuning “ Kembang Matahari" adalah Solihat. Sebenarnya pelopor pembuatan Kerupuk Mie Kembang Matahari adalah ibunya Solihat, namun karena sudah tua, usaha kerupuk Mie tersebut dilanjutkan oleh anaknya yaitu Solihat yang berusia 40 tahun. Karyawan Kerupuk Mie "Kembang Matahari" kurang lebih ada 25 orang yang umumnya rata ibu-ibu usia lanjut. Berdasarkan survey Kerupuk Mie "Kembang Matahari" telah terdaftar sebagai salah satu UKM di Kelurahan Karadenan Kecamatan Cibinong Kabupaten Bogor. Alamat Kerupuk Mie Kuning “ Kembang Matahari” tepatnya yaitu Jalan Kaum Pandak Rt 002/002 Cibinong Bogor. 


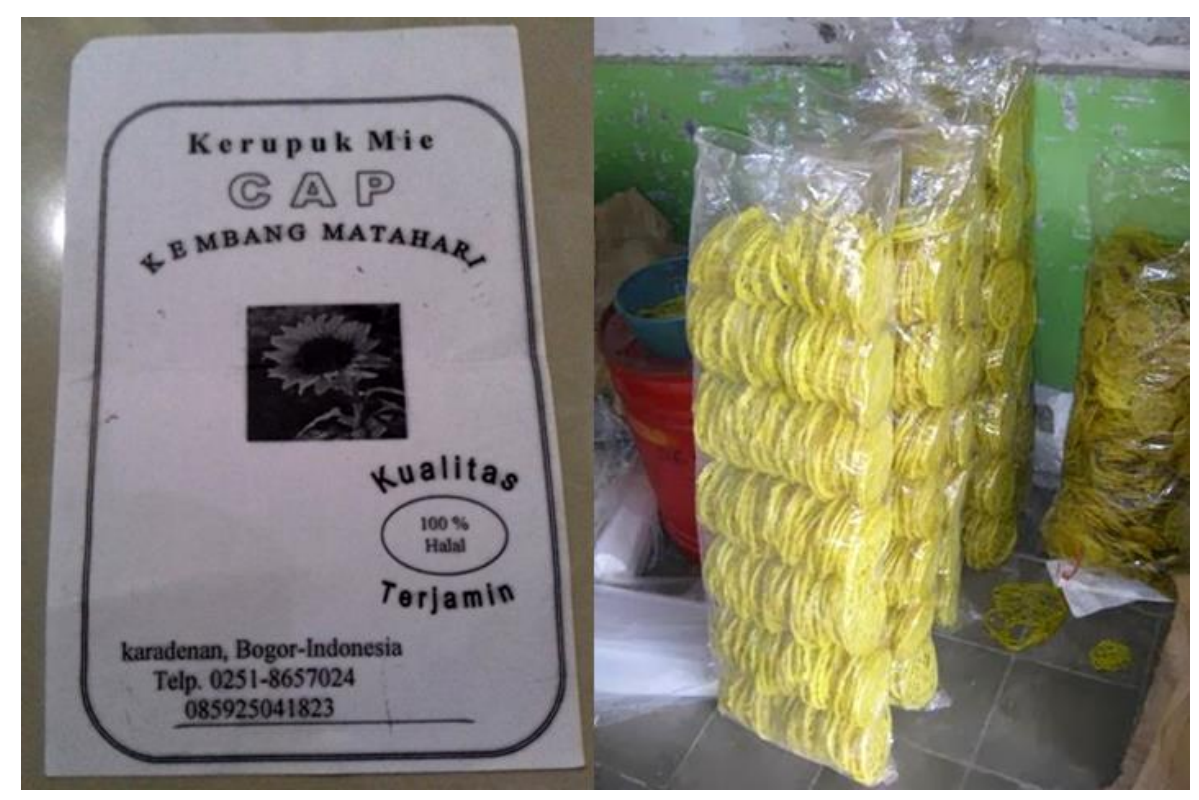

Gambar 2. Pengemasan dan Label Mie Kuning Cap Kembang Matahari

Sumber: Tim Peneliti, 2018

Menurut Solihat, pemilik pabrik Kerupuk Mie "Kembang Matahari”, dalam tiga tahun terakhir penjualan kerupuk mereka menurun. Selain semakin jarangnya warung, juga ada produk-produk tiruan yang membuat produk yang sama. Namun kualitas yang diberikan tidak sama dengan produksi dari Pabrik Kerupuk Mie "Kembang Matahari". Periklanan dan pemasaran yang kurang maksimal membuat Kerupuk Mie "Kembang Matahari" banyak ditiru, dan akhirnya menurunkan penjualannya. Dalam membangun merek Kerupuk Mi "Kembang Matahari”, pemilik usaha tidak memperhatikan secara seksama. Sehingga kemasan yang begitu-begitu saja yang menjadi andalan. Periklanan merupakan penyebaran informasi ataupun ide yang berkaitan tentang suatu gagasan, barang atau jasa, untuk 'membujuk' serta menarik orang agar berfikir, bersikap atau bertindak sesuai dengan keinginan pengiklan (Dawami, Yayah dan Mohamad, 2018:4). Belum adanya prospek Ekspor, menjadikan Kerupuk Mi hanya diproduksi sangat banyak di bulan Ramadhan saja. Sehingga penjualan Kerupuk Mie hanya berkutat pada wilayah Jabodetabek saja.

Berdasarkan survey lapangan, kerupuk Mie Kuning “ Kembang Matahari” rasanya enak, cocok sebagai cemilan. Namun jika melihat pabrik Kerpuk Mie Kuning "Kembang Matahari" yang sesungguhnya, dinilai masih kurang higienis. Peralatan yang digunakan adalah peralatan yang sifatnya konvensional. Hal ini menjadi salah satu penyebab pada tahun 2018, penjualan kerupuk mereka menurun. Selain semakin jarangnya warung, juga ada produk-produk tiruan yang membuat produk yang sama. Namun kualitas yang diberikan tidak sama dengan produksi dari Pabrik Kerupuk Mie "Kembang Matahari". Pemasaran yang kurang maksimal membuat Kerupuk Mie "Kembang Matahari" banyak ditiru, dan akhirnya menurunkan penjualannya. Dalam membangun merek Kerupuk Mie "Kembang Matahari", pemilik usaha tidak memperhatikan secara seksama. Padahal konsep visual logo dan kemasan yang kuat akan memberikan dampak penjualan yang kuat pula (Dawami, 2019). Sehingga kemasan yang begitubegitu saja yang menjadi andalan. Belum adanya prospek Ekspor, menjadikan Kerupuk Mie hanya diproduksi sangat banyak di bulan Ramadhan saja. 


\section{Rumusan Masalah}

Bagaimana bentuk logo lama dan logo baru yang akan menjadi merek jual untuk Kerupuk Mi "Kembang Matahari”?

\section{Tujuan dan Urgensi Penelitian}

Tujuan penelitian ini adalah membentuk konstruksi visual identity melalui logo yang bersumber pada logo yang lama. Memperkenalkan produk dengan desain visual Kerupuk Mie "Kembang Matahari" yang baru merupakan langkah yang dapat dilakukan oleh peneliti untuk menawarkan bentuk identitas Kerupuk Mie "Kembang Matahari”. Konstruksi bentuk logo yang baru menjadi penting untuk dikembangkan guna mendapatkan identitas baru, namun tidak menghilangkan identitas yang lama. Sehingga branding Kerupuk Mie "Kembang Matahari" dapat memenuhi standar identitas untuk Ekspor ke Luar Negeri.

\section{METODE PENELITIAN}

Perancangan dilaksanakan dengan metode penelitian kualitatif secara deskriptif dengan melakukan observasi, wawancara, dokumentasi, studi literatur dan studi kompetitor untuk mendapatkan data sebagai konsep perancangan desain kemasan Kerupuk Mie "Kembang Matahari". Analisis data dengan menggunakan beberapa tahapan yaitu reduksi data, penyajian data, dan verifikasi kesimpulan. Pada tulisan ini hanya kan menyajikan data logo yang akan didiskusikan ke pada mitra untuk dapat didiskusikan lebih lanjut.

\section{HASIL DAN PEMBAHASAN}

Pembuatan aplikasi desain dalam bentuk logo merupakan tugas dari pengkajian dan penciptaan Desain Komunikasi Visual. Desain komunikasi visual adalah ilmu yang mempelajari konsep komunikasi dan ungkapan daya kreatif, yang diaplikasikan dalam berbagai media komunikasi visual dengan mengolah elemen desain grafis terdiri dari gambar (ilustrasi), huruf, warna, komposisi dan layout. Semuanya itu dilakukan guna menyampaikan pesan secara visual, audio, dan audio visual kepada target sasaran yang dituju (Tinarbuko, 2015). Pekerjaan utama desain adalah mentransformasikan atau membentuk kembali peralatan dan lingkungan manusia, dan lebih luas lagi manusia itu sendiri. Maka pengertian desain komunikasi visual adalah suatu aktivitas mulia insan budaya yang diwujudkan dan disampaikan, bagi kepentingan sesama dan alam lingkungan, sebagai rasa syukur terhadap sang pencipta (Safanayong, 2006:98). Pengamatan lapangan yang telah dilakukan oleh tim, kegiatan membangun merek (branding) yang dilakukan oleh Kerupuk Mie "Kembang Matahari" belum dilaksanakan.

Kesadaran akan merek (brand awareness) pada desain yang ada di pemikiran masyarakat Karadenan tentang merek kerupuk juga belum disadari sepenuhnya. Brand awareness merupakan tujuan umum komunikasi pemasaran, adanya brand awareness yang tinggi diharapkan kapanpun kebutuhan kategori muncul, brand tersebut akan dimunculkan kembali dari ingatan yang selanjutnya dijadikan pertimbangan berbagai alternatif dalam pengambilan keputusan (Hadiprawiro, 2018). Dalam brand awarness terdapat logo yang akan mempengaruhi selera pasar. Logo sebagai salah satu elemen visual yang merepresentasikan dirinya agar dikenal kepada masyarakat secara umum (Dawami, 2017). Secara sederhana dapat dilihat dari label yang digunakan oleh Kerupuk Mie "Kembang Matahari", logo yang ada dalam label kurang menarik di masyarakat. Padahal, sebuah entitas menggunakan logo yang berkesan agar dapat berkenalan secara visual dengan masyarakat umum (Dawami, 2017). 
Pengenalan pertama logo Kerupuk Mie "Kembang Matahari” dapat dilihat hanya terdiri dari elemen visual tipografi (tulisan) dengan tipe huruf sans-serif (tidak bersirip). Dimana tipe tersebut dijadikan nama merek dari Kerupuk Mie. Tipe huruf serif (bersirip) digunakan untuk nama "Kerupuk Mie" dan "Kembang Matahari". Gambar yang digunakan adalah gambar foto Kembang Matahari sebagai identitas utama dalam logo Kerupuk Mie "Kembang Matahari”.

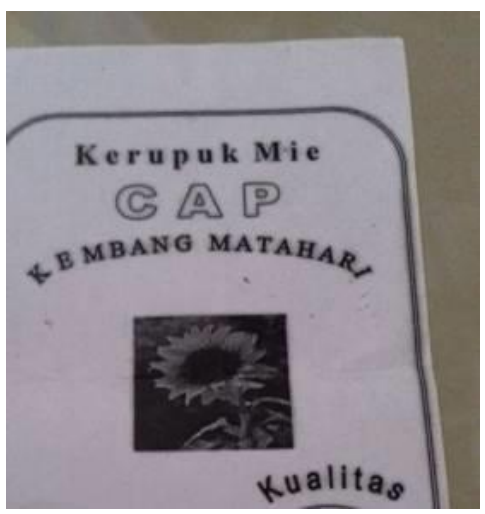

Gambar 3.Logo Lama Mie Kuning Cap Kembang Matahari

Sumber: Tim Peneliti, 2018
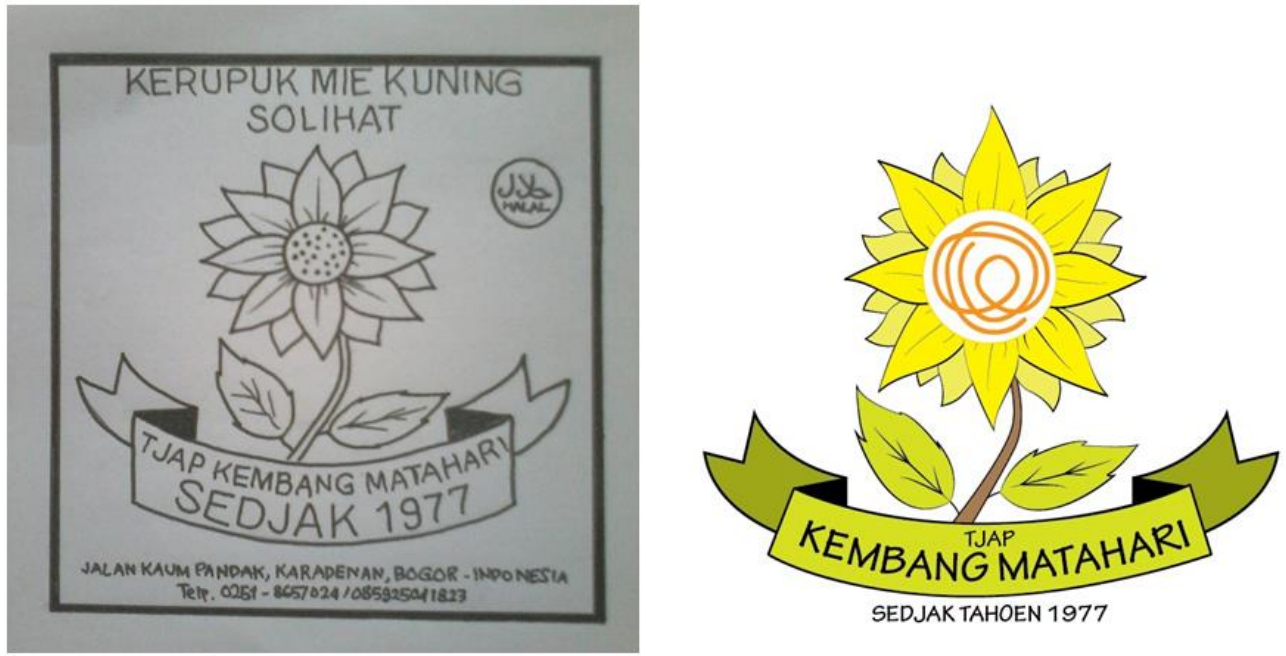

Gambar 4. Draft Logo Mie Cap Kembang Matahari

Sumber: Tim Peneliti, 2019

Bersumber pada logo yang telah ada, tim abdimas mencoba untuk membuat pilihan agar identitas Kerupuk Mie "Kembang Matahari" tidak hilang. Berkonsep pada Kembang Matahari, yang berarti bunga matahari. Bunga matahari di buat dengan bentuk visual bunga matahari. Bertumpu pada gambar bunga matahari, ditengahnya dibuat bentuk yang menyerupai kerupuk dengan warna orange, yang memiliki makna semangat. Konsep yang ditawarkan adalah dengan menggunakan tema "Vernakular". Secara etimologis kata Verna berasal dari bahasa latin yang artinya home born slave (Nuttgents, 1993:125). Kata Vernakular juga berasal dari (latin) berarti asli (native) (Sani \& Supriyadi \& Rukayah, 2015:104). Dalam ilmu bahasa (Linguistik), bahasa vernakular mengacu pada penggunaan bahasa untuk waktu, tempat atau kelompok lokal/tertentu. Konsep logo vernakular dari Kembang Matahari, dibuat dengan bentuk visual 
vernakular dengan ciri seperti tempo dahulu. Maka terbentuklah logo yang sesuai dengan konsep vernakular.

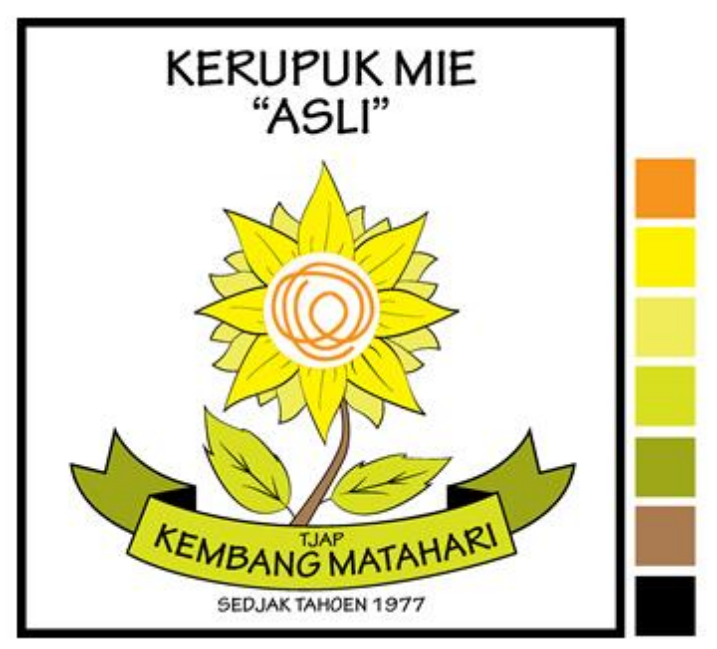

Gambar 5. Warna Logo Mie Kuning Cap Kembang Matahari Sumber: Tim Peneliti, 2019

Setelah menganalisis data, ditemukan, ditemukan sebuah kata kunci "Asli" untuk perancangan desain logo. Konsep "Asli" dalam perancangan desain logo ini bermakna sesuatu yang bisa dipercaya dan aplikasi visual yang menggunakan tema vernakular yang berarti asli. Hasil dari perancangan desain logo ini adalah upaya untuk meningkatkan citra dari produk Kerupuk Mie "Kembang Matahari". Konsep "Asli" kemudian diaplikasikan ke logo baru yang menunjukkan ke-asli-an dari Kerupuk Mie. Perbandingan logo lama dengan tawaran logo baru dari Kerupuk Mie dapat dilihat dibawah ini:

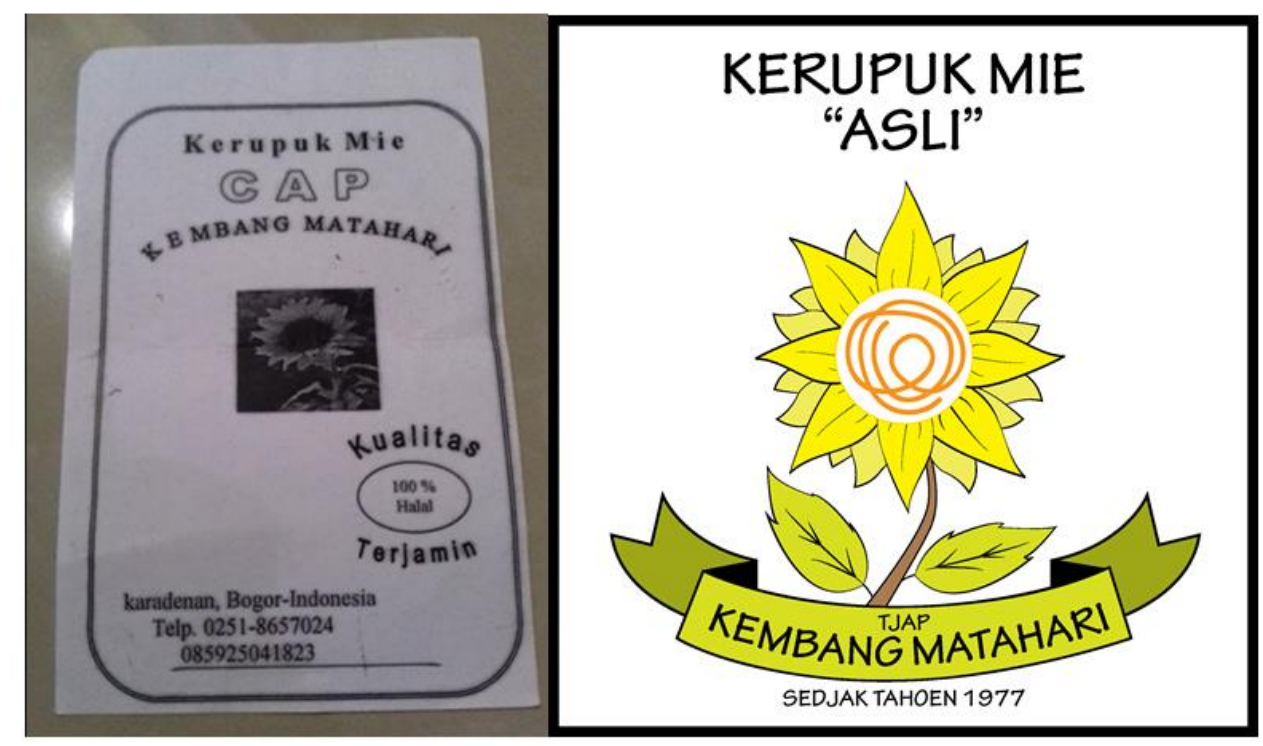

Gambar 6. Perbandingan Logo Lama dengan Logo Baru

Mie Kuning Cap Kembang Matahari

Sumber: Tim Peneliti, 2019 


\section{KESIMPULAN DAN SARAN KESIMPULAN}

Permasalahan utama dari Logo Kerupuk Mie "Kembang Matahari" yang telah ada, membuat visual identity dari Kerupuk Mie "Kembang Matahari" menjadi kurang menarik. Pembentukan logo yang berdasarkan pada wawancara serta konstruksi berfikir pemilik dari Kerupuk Mie "Kembang Matahari" menjadi salahh satu cara untuk menguatkan visual identity dari Kerupuk Mie "Kembang Matahari". Bentuk logo yang baru ini dapat diaplikasikan ke media promosi yang digunakan oleh Kerupuk Mie "Kembang Matahari" untuk meningkatkan nilai jual yang menurun beberapa tahun terakhir. Bentuk logo vernakular akan membuat konstruksi visual dapat bertema asli namun modern secara bentuk. Setelah menganalisis data, ditemukan, ditemukan sebuah kata kunci "Asli" untuk perancangan desain logo maupun tipenya. Konsep "Asli" dalam perancangan desain logo ini bermakna sesuatu yang bisa dipercaya. Hasil dari perancangan desain kemasan ini adalah upaya untuk meningkatkan citra dari logo Kerupuk Mie "Kembang Matahari”.

\section{SARAN}

Penelitian serta perancangan dapat dilanjutkan dengan media-media dan konsep kreatif yang lebih baik untuk membentuk konstruksi pemasaran yang baik ke depannya. Bentuk-bentuk kembang matahari harus lebih banyak dieksplor dalam penelitian lanjutan serta aplikasinya pada pengabdian di tahun-tahun berikutnya.[]

\section{Ucapan Terima Kasih (Acknowledgement)}

Apresiasi dan terima kasih kepada Direktorat Riset dan Pengabdian Masyarakat, Dirjen Penguatan Riset dan Pengembangan, Kementerian Riset, Teknologi dan Pendidikan Tinggi dan yang telah membiayai kegiatan Pengabdian kepada Masyarakat (PPM) Tahun 2019 dengan judul: "Branding Kerupuk Mie "Kembang Matahari" Menuju Pasar Ekspor". Terima kasih juga kepada LLDIKTI Wilayah III Jakarta dan Lembaga Penelitian dan Pengabdian Masyarakat Universitas Indraprasta PGRI yang telah membantu kegiatan penelitian ini melalui Kontrak Penelitian: Nomor: 16/AKM/PNT/2019, Tanggal 27 Maret 2019. Dan Surat Perjanjian/Kontrak Penelitian UNINDRA Nomor: 0409/SKP.LT/LPPM/UNINDRA/III/2018, Tanggal 12 Maret 2018. Tulisan ini merupakan publikasi dari program Hibah Pengabdian Terhadap Masyarakat tahun 2019. Dengan demikian, kami berterima kasih untuk pendanaan pada program pengabdian ini yang sepenuhnya didanai oleh DRPM Kementerian Riset, Teknologi, dan Pendidikan Tinggi Indonesia. Peneliti juga mengucapkan banyak terima kasih kepada LPPM Universitas Indraprasta PGRI atas semua bantuan dan pendampingan yang diberikan selama pengabdian terhadap masyarakat ini berlangsung. Kepada setiap pihak yang membantu dalam keberjalanan pengabdian ini sampai menyelesaikan program ini. Terima kasih.

\section{DAFTAR PUSTAKA}

Dawami, A. K. (2019). Perancangan promosi wisata pendakian gunung merbabu melalui desa cuntel. Jurnal Magenta, 3(1), 387-396, Januari 2019.

Dawami, A. K. \& Rukiah, Y. \& Andrijanto, M.S. . (2018). Analisis kampanye hari disabilitas internasional (hdi) tahun 2017 kabupaten klaten. Jurnal Desain 6 (01), 1-9, SeptemberDesember 2018 
Dawami, A. K. (2017). Logo sebagai komunikasi visual dari identitas organisasi difabel tuli. Jurnal Magenta, 1(02), 133-141, Juli 2017.

Denzin, N.K. \& Yvonna S.L. (2009). Handbook of qualitative research, Yogyakarta: Pustaka Pelajar.

Hadiprawiro, Y. (2018). Desain logo dan maskot "difabel klaten" sebagai brand awarness kampanye sosial peduli masyarakat disabilitas di klaten, jawa tengah. Jurnal Desain 5 (02), 135-144, Januari 2018

Nuttgents, P. (1993). The nature of architecture. Dalam B. Farmer dan H. Louw (Ed.), Companion to contemporary architectural thought. London dan New York: Routledge.

Safanayong, Y.. (2006). Desain Komunikasi Visual Terpadu. Jakarta: Arte Intermedia

Sani, AA \& Supriyadi, B \& Rukayah RS. (2015). Bentuk dan proporso pada perwujudan arsitektur vernakular bugis. Jurnal Teknik Sipil dan Perencanaan 17 (2), 99-110.

Tinarbuko, S.. (2015). DEKAVE: Desain Komunikasi Visual, Penanda Zaman Masyarakat Global. Yogyakarta:CAPS. 